\title{
Penetration Depth Variation in Atomic Layer Deposition on Multiwalled Carbon Nanotube Forests
}

\author{
David Alan Kane \\ Brigham Young University
}

Follow this and additional works at: https://scholarsarchive.byu.edu/etd

Part of the Physics Commons

\section{BYU ScholarsArchive Citation}

Kane, David Alan, "Penetration Depth Variation in Atomic Layer Deposition on Multiwalled Carbon Nanotube Forests" (2018). Theses and Dissertations. 7124.

https://scholarsarchive.byu.edu/etd/7124

This Thesis is brought to you for free and open access by BYU ScholarsArchive. It has been accepted for inclusion in Theses and Dissertations by an authorized administrator of BYU ScholarsArchive. For more information, please contact ellen_amatangelo@byu.edu. 
Penetration Depth Variation in Atomic Layer Deposition on Multiwalled Carbon Nanotube Forests

David Alan Kane

A thesis submitted to the faculty of Brigham Young University in partial fulfillment of the requirements for the degree of

Master of Science

Richard R. Vanfleet, Chair

Robert C. Davis

Matthew R. Linford

Department of Physics and Astronomy

Brigham Young University

Copyright (C) 2018 David Alan Kane

All Rights Reserved 


\author{
ABSTRACT \\ Penetration Depth Variation in Atomic Layer Deposition \\ on Multiwalled Carbon Nanotube Forests \\ David Alan Kane \\ Department of Physics and Astronomy, BYU \\ Master of Science
}

\begin{abstract}
Atomic Layer Deposition (ALD) of $\mathrm{Al}_{2} \mathrm{O}_{3}$ on tall multiwalled carbon nanotube forests shows concentration variation with the depth in the form of discrete steps. While ALD is capable of extremely conformal deposition in high aspect ratio structures, decreasing penetration depth has been observed over multiple thermal ALD cycles on $1.3 \mathrm{~mm}$ tall multiwalled carbon nanotube forests. SEM imaging with Energy Dispersive X-ray Spectroscopy elemental analysis shows steps of decreasing intensity corresponding to decreasing concentrations of $\mathrm{Al}_{2} \mathrm{O}_{3}$. A study of these steps suggests that they are produced by a combination of diffusion limited delivery of precursors with increasing precursor adsorption site density as discrete nuclei grow during the ALD process. This conceptual model has been applied to modify literature models for ALD penetration on high aspect ratio structures, allowing several parameters to be extracted from the experimental data. The Knudsen diffusion constant for trimethylaluminum (TMA) in these carbon nanotube forests has been found to be $0.3 \mathrm{~cm}^{2} \mathrm{~s}^{-1}$. From the profile of the $\mathrm{Al}_{2} \mathrm{O}_{3}$ concentration at the steps, the sticking coefficient of TMA on $\mathrm{Al}_{2} \mathrm{O}_{3}$ was found to be 0.003 .
\end{abstract}

Keywords: carbon nanotubes, Knudsen diffusion, atomic layer deposition, sticking coefficient 


\section{ACKNOWLEDGEMENTS}

I could not have done this research projet by myself. I'd like to thank my advisor, Richard Vanfleet for significant time spent with me and on writing, advice, teaching, as well as for letting me take the project in a somewhat different direction than originally intended. Thanks to Robert Davis I found the research group, and his efforts in advising me are also greatly appreciated. Classes from Matt Linford, Richard Vanfleet, Robert Davis, and Jeff Farrer were particularly helpful in providing me with the skills to carry this project out. I appreciate the dedicated work of Shelena Shamo and Nan Ellen Ah You, which has taken many different forms. I'd also like to thank my wife, Lis for her loving support during the process. 


\section{TABLE OF CONTENTS}

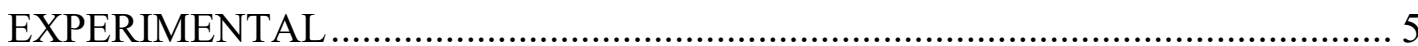

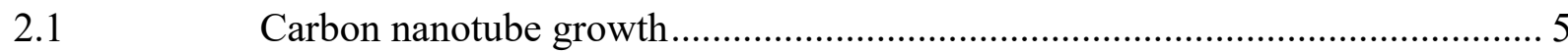

$2.2 \quad$ Ozone

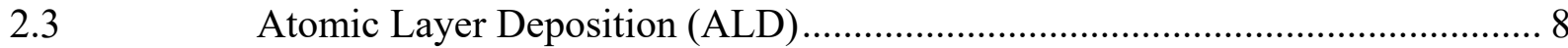

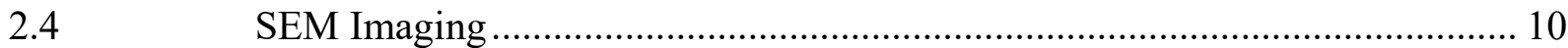

Determination of nucleation site density ................................................ 11

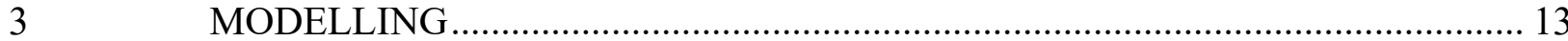

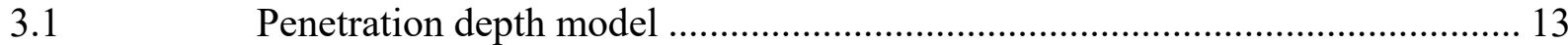

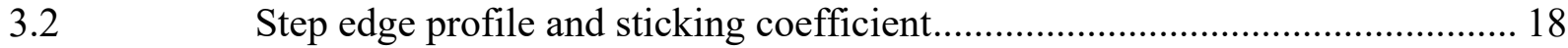

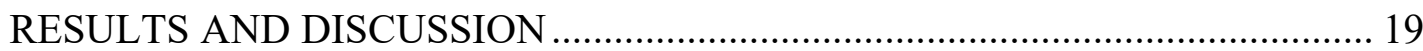

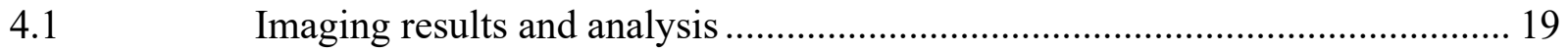

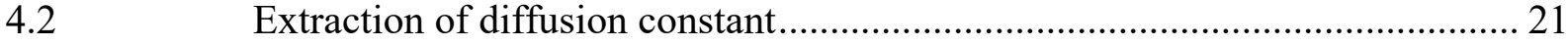

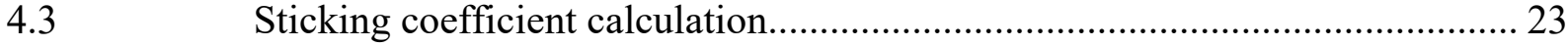

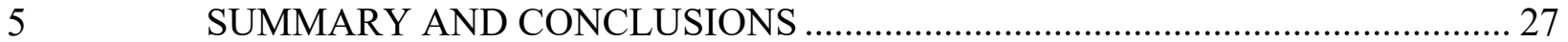

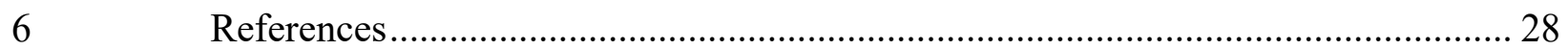




\section{LIST OF FIGURES}

Figure 1 Number of Atomic Layer Deposition or Atomic Layer Epitaxy papers published per year

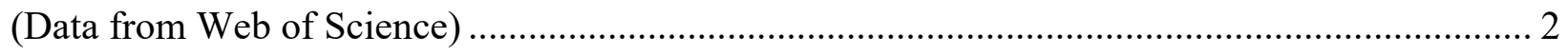

Figure 2 A SEM of a multiwalled carbon nanotube forest ........................................................ 7

Figure 3 The average nanotube diameter as a function of depth in the forest............................... 8

Figure 4 Carbon nanotube forests with different numbers of ALD cycles. 256 ms TMA doses were used in all cases. Left: 4 cycles Middle: 7 cycles Right: 10 cycles. Red dots indicate edges of steps.

Figure 5 An unsatisfactory image of a MWCNT forest which should have ALD steps. ............. 11

Figure 6 A typical STEM of a MWCNT used for nucleation site density calculations ............... 12

Figure 7 Graphical description of model: Each ALD cycle makes the nuclei grow, causing them

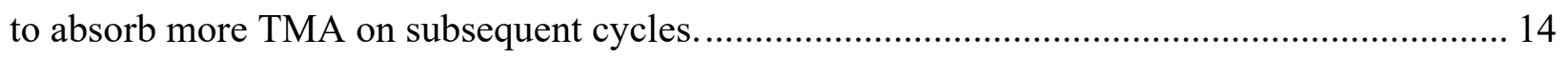

Figure 8 Carbon nanotube forests with 10 ALD cycles and different TMA doses A: 64 ms. B: 128

ms. C: 256 ms. D: 512 ms. Red dots denote edges between steps.......................................... 20

Figure 9 A: Cycle penetration depths from four MWCNT forests, each with 10 ALD cycles with 64, 128, 256, and $512 \mathrm{~ms}$ TMA doses. B: Data from the $64 \mathrm{~ms}$ dose sample, along with the model fit. C: Data from the 512ms dose sample, along with the model fit. ........................................ 22

Figure 10 Effect of sticking coefficient on step coverage profile. Parameters chosen for

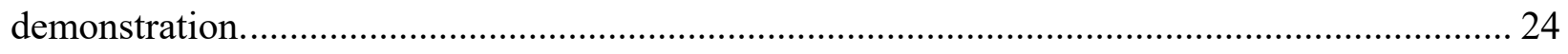

Figure 11 A: SEM intensity profile from MWNCT forest with 10 aluminum oxide ALD cycles and 256 ms TMA doses. B and C are segments of the intensity profile in A with the intensity fit used to find $\beta_{0}$.. 25 
Figure 12 Sticking coefficient values for different ALD cycles. Note that systematic error is much

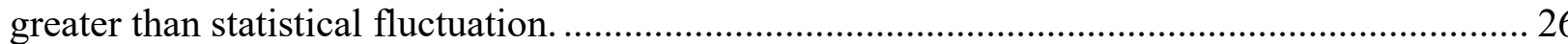




\section{INTRODUCTION}

Numerous applications including capacitors ${ }^{1-3}$, catalysts $^{4-6}$, and batteries ${ }^{7-9}$ can benefit from the deposition of thin films on high aspect ratio or nanostructured substrates. Atomic layer deposition (ALD) ${ }^{10}$ allows a wide variety of materials to be deposited on high aspect ratio structures at relatively low temperatures with excellent control over film thickness. ${ }^{11}$ Significant work has been done on modelling transport in ALD and related processes on nanostructured materials ${ }^{12}$ but experimentally based understanding is a work in progress.

ALD has been used to manufacture high aspect ratio capacitors for DRAM applications. Seidi et al. ${ }^{13}$ demonstrated the feasibility of using ALD to deposit the dielectric of a capacitor in a trench to make silicon-insulator-silicon capacitors. The trench aspect ratio was approximately 30 . Similar techniques appear in various patents ${ }^{14-16}$. ALD has also been used to deposit diffusion barriers for interconnects ${ }^{10}$. Elam et al. ${ }^{17}$, based on both simulations and experiments, reported that the required dose to coat a high aspect ratio structure is proportional to the aspect ratio squared. However, in practice, it appears that many ALD processes on high aspect ratio structures are optimized by past experience or trial and error.

Deposition on high aspect ratio structures can be challenging. Depositing material on the outside surface of the structure is much easier than depositing it conformally throughout the material. In most deposition techniques, diffusion of the precursor and its deposition reaction occur simultaneously. Because the precursor reacts within some amount of time, it can only diffuse a certain distance before reacting, limiting the depth into a structure the material can be deposited. Line of sight deposition techniques, including most PVD techniques coat only the outside of nanostructured materials. Chemical vapor deposition (CVD) is not typically line of sight because the gaseous precursors used can diffuse into nanostructured materials before reacting. ${ }^{18}$ The 
reaction rate in CVD can be controlled by adjusting the temperature. Decreasing the reaction rate improves conformality on high aspect ratio structures because it allows the precursor gasses more time to diffuse before reacting. ${ }^{19}$ Yanguas-Gil et. al. showed that very high aspect ratio structures can be coated by CVD by decreasing the reaction rate, at the cost of a dependence on some specific requirements on the precursor vapor pressure..$^{20}$ This strategy may work well in many situations but as aspect ratios increase, it forces a compromise between step coverage (top-bottom thickness difference) and deposition rate.

Atomic layer deposition was independently discovered by Prof. Aleskovskii's group in the Soviet Union and by Dr. Tuomo Suntola in Finland. ${ }^{21}$ Suntola's commercially motivated group needed to prepare high quality films of $\mathrm{ZnS}$ with good thickness control for use in electroluminescent displays. ALD (previously known as ALE or Atomic Layer Epitaxy) became much more popular after Microchemistry offered the F-120 ALD reactor for sale in 1987:

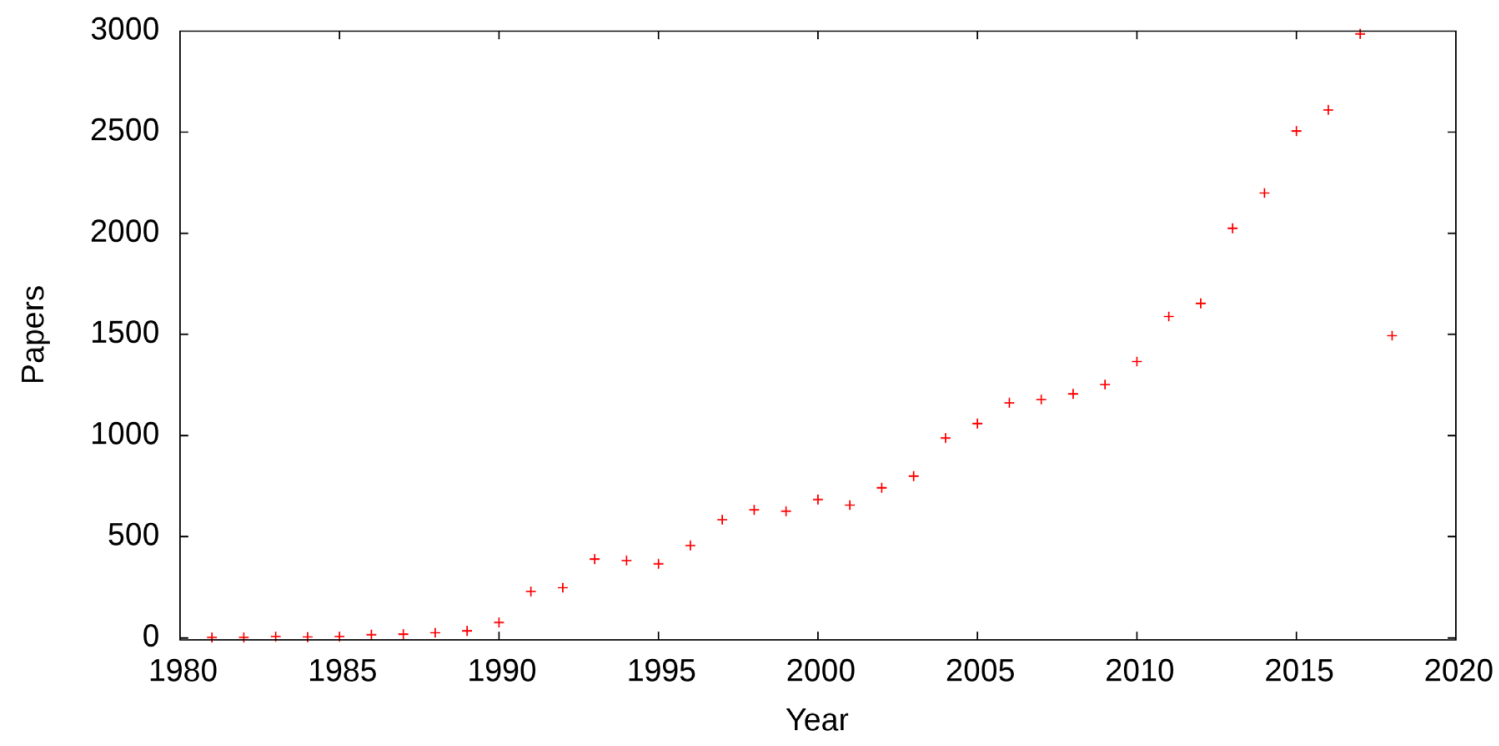

Figure 1 Number of Atomic Layer Deposition or Atomic Layer Epitaxy papers published per year (Data from Web of Science) 
Several authors have discussed the ALD precursor dose needed to coat high aspect ratio structures $^{22-29}$ and mathematical models have been used to calculate these dose requirements. Roy Gordon developed a model for cylindrical pores which assumes that precursor molecules enter the pore and immediately react with the first unreacted site encountered and that the pressure is low enough that transport occurs by Knudsen diffusion (that is, that the molecules primarily collide with solid objects rather than other gas molecules).$^{30}$ Angel Yanguas-Gil et al. calculated the required precursor dose using a model that incorporated Knudsen diffusion and a finite sticking coefficient. ${ }^{31}$ The sticking coefficient is the probability that an impinging precursor will react with a reactive site on the surface and has been reported for a few ALD processes. ${ }^{32-36}$ Vertically aligned multiwalled carbon nanotube (MWCNT) forests offer an extreme high aspect ratio test structure for ALD. The ratio of forest height to the spacing between nanotubes can exceed 10,000. Additionally MWCNT forests with various coatings are materials systems incorporated into devices and systems for many applications including capacitors ${ }^{2}, \mathrm{MEMS}^{37}$, brain computer interfaces $^{38}$, and mechanically compliant thermal conductors ${ }^{39}$.

Numerous ALD processes on carbon nanotubes have been reported, although, in many cases not using forests. Conformal coatings, islands, or nodular films are observed depending on the ALD process, the nanotube growth, and the choice of nanotube surface pretreatment ${ }^{40} \mathrm{~A}$ few of these studies address the problem of diffusion in carbon nanotube forests. Stano et al. uniformly coated $1.5 \mathrm{~mm}$ tall carbon nanotube forests by ALD after removing the forests from the substrate to allow a flow through geometry for precursor gasses. Conversely, a number of authors report deposition on carbon nanotube forests without removing them from the substrate. The forests are typically under $100 \mu \mathrm{m}$ tall, and well beyond 20 ALD cycles were performed, making it unlikely that the authors would have seen the intensity step behavior we report. ${ }^{41-44}$ Typically, no details on how 
the dose used was chosen are given. It is possible that in many of these cases, comparison to a model could have saved experimental time or costly precursors.

Important features of an ALD process include the nucleation delay which is a function of the underlying surface and how it interacts with the precursors and the steady state growth per cycle, a property of the process. While the nucleation delay and subsequent growth can be quite complicated, a basic model incorporating chemically reactive sites at which the precursors can chemisorb $^{10}$ is often helpful. Often, increasing the number of reactive sites on a surface by a pretreatment enables more conformal films to be grown. ${ }^{45}$ Such pretreatments are frequently used prior to ALD on carbon nanotubes. ${ }^{10,45-47}$ Several methods to functionalize carbon nanotubes to improve or produce these sites have been reported ${ }^{45,48,49}$. Kanyal et al. reported that ozone treatment on patterned MWCNT forests produces $\mathrm{C}-\mathrm{O}, \mathrm{C}=\mathrm{O}$, and $\mathrm{O}-\mathrm{C}=\mathrm{O}$ carbon moieties, causing increased adsorption site density for a TMA/tris(tert-butoxyl)silanol $\mathrm{SiO}_{2}$ ALD process. ${ }^{50} \mathrm{An}$ increase in ALD adsorption site density for the TMA/water process on ozone treated carbons has also been reported for highly oriented pyrolytic graphite ${ }^{51}$ and doped MWCNTs ${ }^{52}$.

The Knudsen diffusion constant is needed to make use of the Yanguas-Gil model. Theoretical calculations of the Knudsen diffusion constant based on geometry, surface diffusion, adsorption and desorption, and other thermodynamic surface considerations have been carried out. ${ }^{12}$ For the case of MWCNT forests, Szmyt et al. derived the Knudsen diffusion constant for gasses in arrays of cylinders, finding: ${ }^{53}$

$$
D=\frac{\pi v_{t h}}{4 \sigma d}
$$

\section{Equation 1-1}


where $v_{\text {th }}$ is the thermal velocity, $\sigma$ is the areal density of carbon nanotubes, and $\mathrm{d}$ is the carbon nanotube diameter.

We have investigated the infiltration of these tall CNT forests using the TMA/water thermal $\mathrm{Al}_{2} \mathrm{O}_{3}$ ALD process. We observed depth dependent concentration variations in the deposited alumina that occurred in discrete steps. Experiments suggest that each step is produced by a single ALD cycle. We find that step depth and spacing is controlled by the dose of the limiting reactant and is thus transport (or diffusion) controlled. We extended prior published diffusion limited deposition models by assuming that the number of adsorption sites grows in proportion to the surface area of the $\mathrm{Al}_{2} \mathrm{O}_{3}$ nuclei. Analysis using these adsorption site models allows extraction of the Knudsen diffusion coefficient for TMA in these CNT forests as well as the sticking coefficient for TMA in the TMA/water process. The diffusion constant found in these CNT forests was $0.3 \mathrm{~cm}^{2} \mathrm{~s}^{-1}$ and the extracted sticking coefficient for TMA in the TMA/water ALD process was 0.003 .

\section{EXPERIMENTAL}

MWCNT forests were grown on silicon wafers. The MWCNT forests were treated with ozone, processed using TMA/water ALD, and the resultant samples were analyzed by cross sectional scanning electron microscopy (SEM).

\subsection{Carbon nanotube growth}

Carbon nanotube growth used previously described methods. ${ }^{54,55}$ To prepare the substrate for MWCNT growth, $50 \mathrm{~nm}$ of $\mathrm{Al}_{2} \mathrm{O}_{3}$ were deposited on a (100) silicon wafer by e-beam evaporation (Denton Vacuum). Depositing the $\mathrm{Al}_{2} \mathrm{O}_{3}$ by other methods is a possibility. Amama et. al. reported that the nanotube growth rate on sputtered $\mathrm{Al}_{2} \mathrm{O}_{3}$ was slightly greater than the growth rate on e- 
beam deposited $\mathrm{Al}_{2} \mathrm{O}_{3}$, but $\mathrm{ALD}$ deposited $\mathrm{Al}_{2} \mathrm{O}_{3}$ had a much lower CNT growth rate. ${ }^{56}$ Oxygen plasma treatment on the $\mathrm{Al}_{2} \mathrm{O}_{3}$ has been reported to improve carbon nanotube growth rates. ${ }^{57}$ Photolithography was used to pattern AZ3330, a positive photoresist (Integrated Micro Materials) on the wafer after $\mathrm{Al}_{2} \mathrm{O}_{3}$ deposition with $1 \mathrm{~cm}^{2}$ circular holes. $4 \mathrm{~nm}$ of iron were then deposited by resistive thermal evaporation (cryopumped system). To lift off the iron, the wafer was sonicated in N-Methyl-2-Pyrrolidone (Sigma-Aldrich) for 15 minutes. The wafer was then rinsed by placing it in water from a Millipore Academic water purifier (MilliporeSigma) for 100 minutes.

Carbon nanotube growth was performed at atmospheric pressure in a tube furnace. The wafers were first heated to $750{ }^{\circ} \mathrm{C}$ in a hydrogen atmosphere. After the furnace temperature reached 750 ${ }^{\circ} \mathrm{C}$, ethylene and hydrogen with a volumetric flow rate ratio of 1.08:1 with a nominal total flow of $649 \mathrm{sccm}$ were flowed for 50 minutes in a quartz tube with an inside diameter of $24.5 \mathrm{~mm}$. The MWCNT forests were cooled to $200{ }^{\circ} \mathrm{C}$ in a hydrogen atmosphere.

The carbon nanotube diameter was measured from SEM images (FEI Verios G4 UC). At least three images were taken at each depth in the forest with the column in immersion mode at a beam energy of $10 \mathrm{kV}$, beam current of 50pA, horizontal field width of 829 nanometers and a resolution of $3072 \times 2048$. A typical image is shown in Figure 2. 


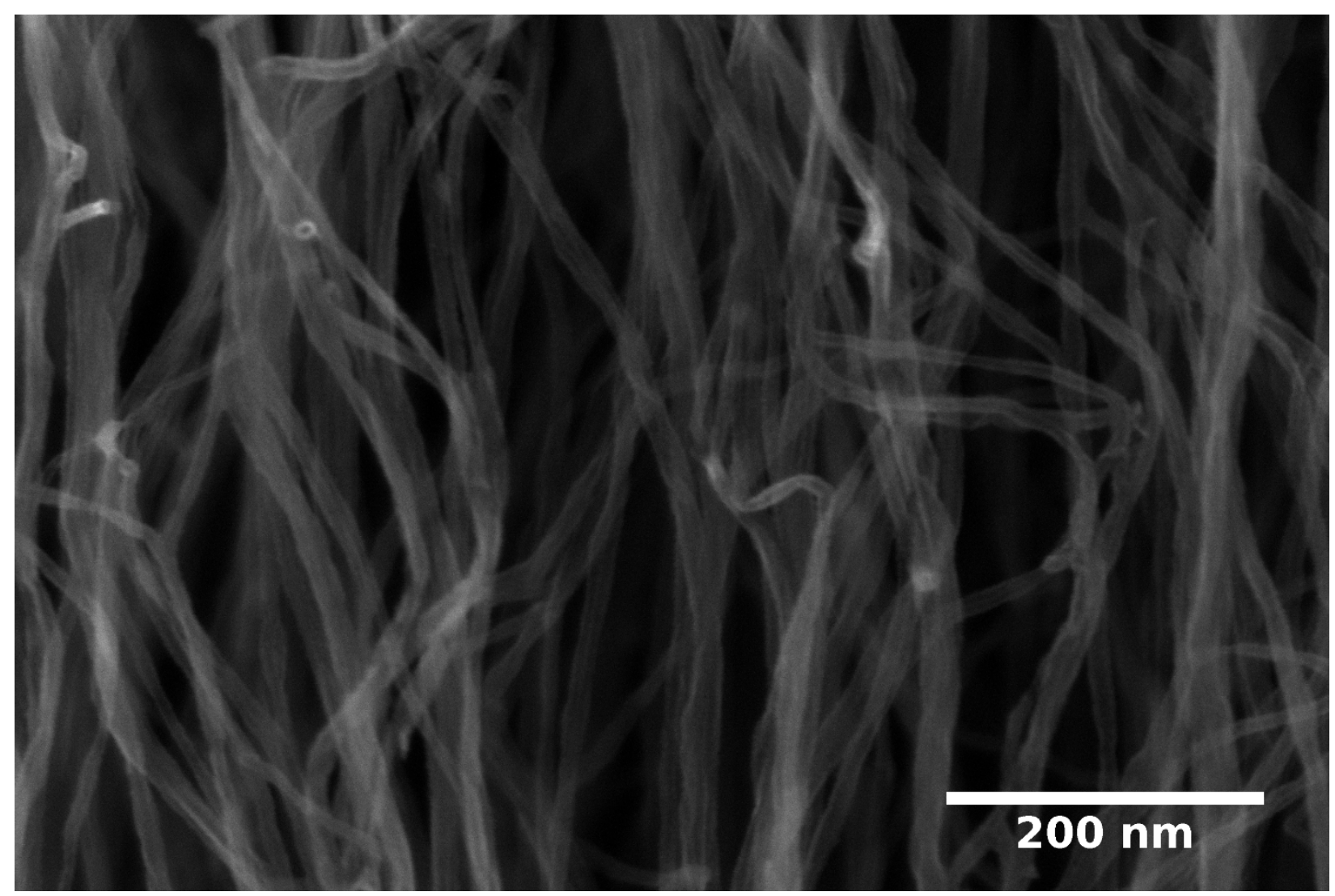

Figure 2 A SEM of a multiwalled carbon nanotube forest

The ImageJ software was used to measure the nanotube diameters manually. At least 50 nanotubes were measured at each depth in the forest to find the average diameter. The diameter as a function of depth in the forest is in Figure 3. 


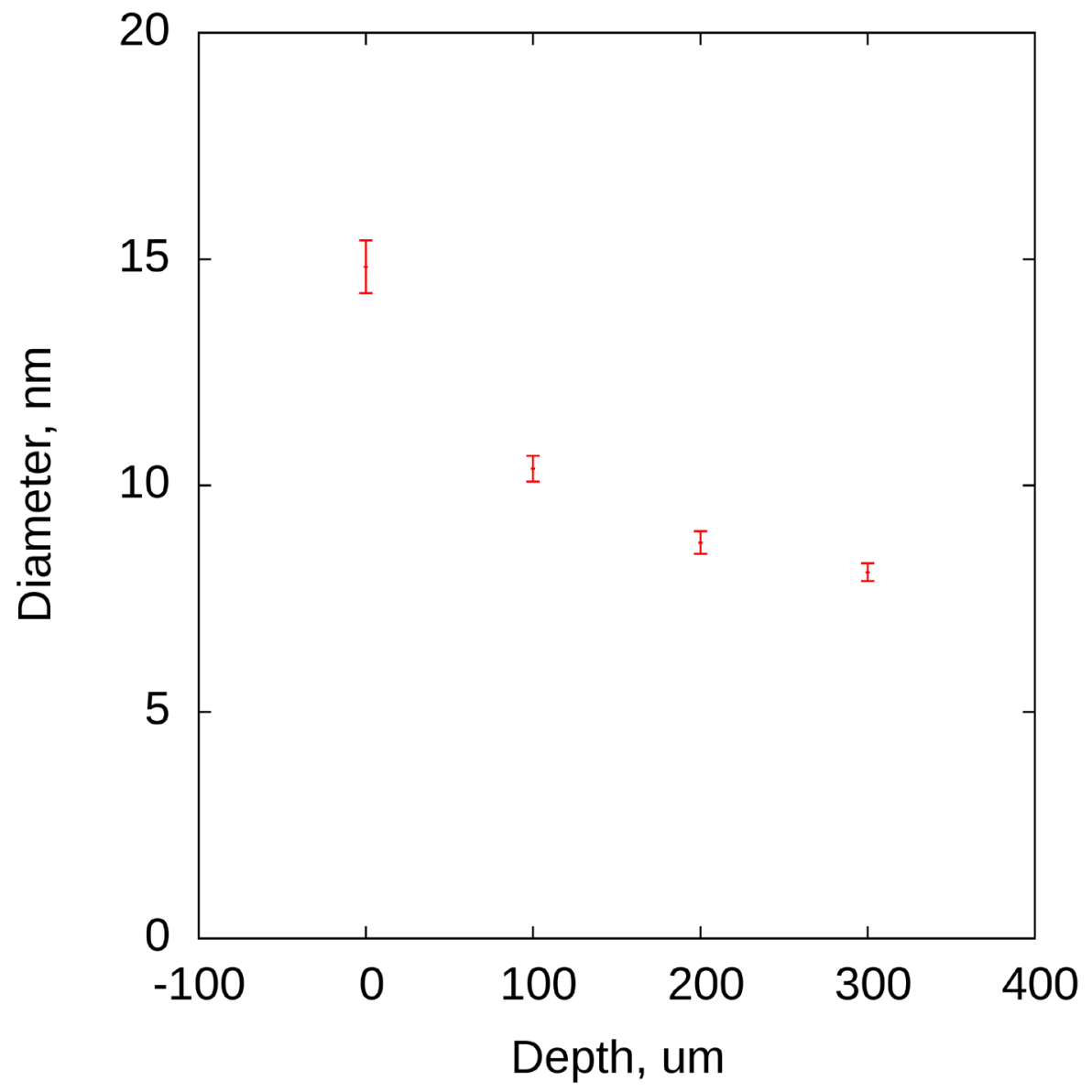

Figure 3 The average nanotube diameter as a function of depth in the forest.

\section{$2.2 \quad$ Ozone}

The wafers with MWCNT forests were placed in a tube through which $4.4 \mathrm{~g} / \mathrm{h}$ of ozone from a commercial ozone generator (Absolute Ozone) was flowed at room temperature and atmospheric pressure for 30 minutes. These parameters were chosen based on Kanyal et. al.'s characterization of the ozone treatment process. ${ }^{50}$

2.3 Atomic Layer Deposition (ALD) 
Dynamic thermal ALD of $\mathrm{Al}_{2} \mathrm{O}_{3}$ was performed in a commercial ALD-150LX system (Kurt J. Lesker Company). This ALD system has a process chamber containing a substrate heater for a 6 " circular substrate which can be heated to $500{ }^{\circ} \mathrm{C}$. During an ALD process, the process chamber is constantly purged with inert gas (nitrogen was used for this study although the system can use argon with a software change to adjust the MFCs). The purge flow prevents deposition on the analytical viewports and the door. Additionally, inert gas purges flow past two precursor sources. All precursor delivery lines are heated. The chamber is pumped continuously during ALD processes. Optionally, the throttle valve installed after the roughing valve can be used to adjust the chamber pressure. Because the capacitance manometer in the process chamber reads pressures up to 10 torr only, it is not possible to control the pressure above this point. For this study, the throttle valve was in the fully open position.

The system has two 'sources' where a precursor can be installed, SRC3 and SRC1. SRC3 is an oven which can be heated if needed. This functionality was not used in this study. SRC3 has two $1 / 4$ " VCR connections which can either be used for a bubbler, or each one can be connected to a simple, single connection precursor cylinder as was done in this study. In this study, the TMA was installed on SRC3. SRC1 has a single 1/4" VCR connection for a precursor cylinder. In this study, water was installed on SRC1.

After the substrate heater of the ALD system was brought to $332^{\circ} \mathrm{C}$, the MWCNT forests were placed in the system. From this point until the samples were removed, the chamber was continuously pumped and purged. A 10 minute delay before the ALD process began allowed the forests to reach the temperature of the substrate heater. An ALD cycle consisted of a trimethylaluminum (TMA) (Strem Chemicals) dose of a fixed duration between 64 and $512 \mathrm{~ms}$, a $120 \mathrm{~s}$ ultrahigh purity nitrogen purge, a $1 \mathrm{~s}$ water dose, and another $120 \mathrm{~s}$ ultrahigh purity nitrogen 
purge. Each TMA precursor dose produced a pressure spike of around 270 millitorr. Water doses produced around 200 millitorr pressure spikes. Both precursors were at room temperature $\left(\sim 25^{\circ}\right.$ C). Two series of samples were prepared: one varying the number of cycles and one varying the TMA dose time.

\section{$2.4 \quad$ SEM Imaging}

To view the samples in an SEM (FEI Verios G4 UC), the silicon substrates were cleaved through the MWCNT forest to expose a cross section. An acceleration voltage of $500 \mathrm{~V}$ was chosen to obtain sufficient contrast to view the steps. Typical cross section images can be seen in Figure 4 .

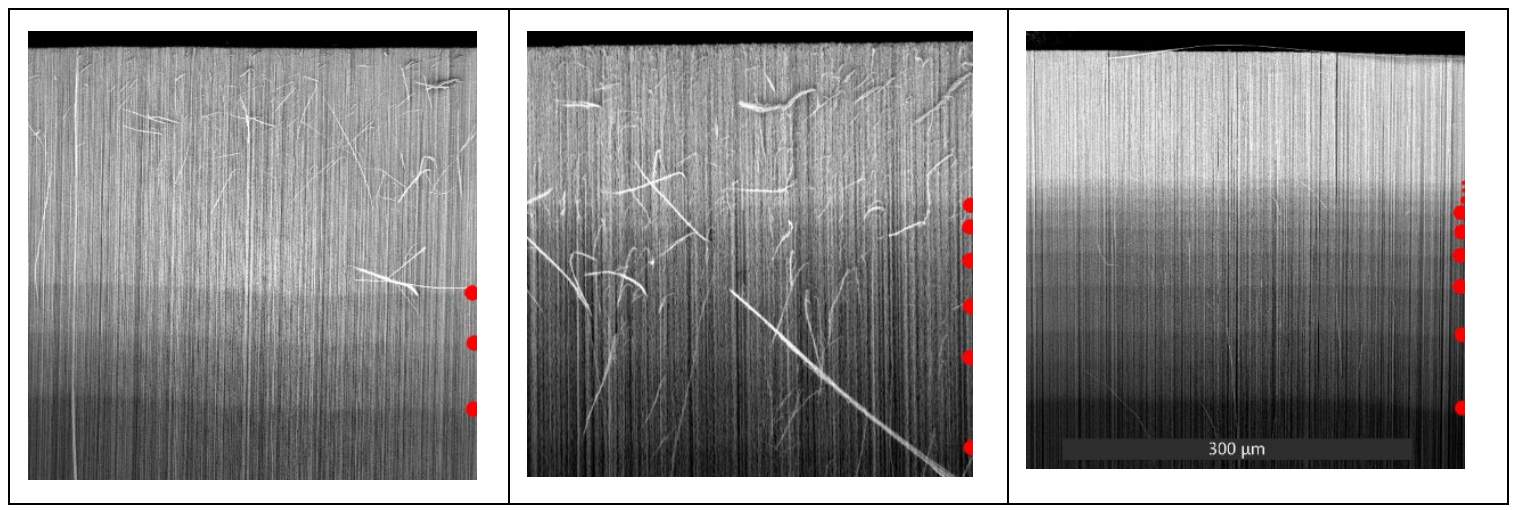

Figure 4 Carbon nanotube forests with different numbers of ALD cycles. $256 \mathrm{~ms}$ TMA doses were used in all cases. Left: 4 cycles Middle: 7 cycles Right: 10 cycles. Red dots indicate edges of steps.

Acquiring satisfactory SEM images is often problematic. Frequently, cleaving the wafer to break a nanotube forest produces surfaces that are rough or covered with incorrectly aligned nanotubes, rendering them useless for imaging. See Figure 5 as an example. 


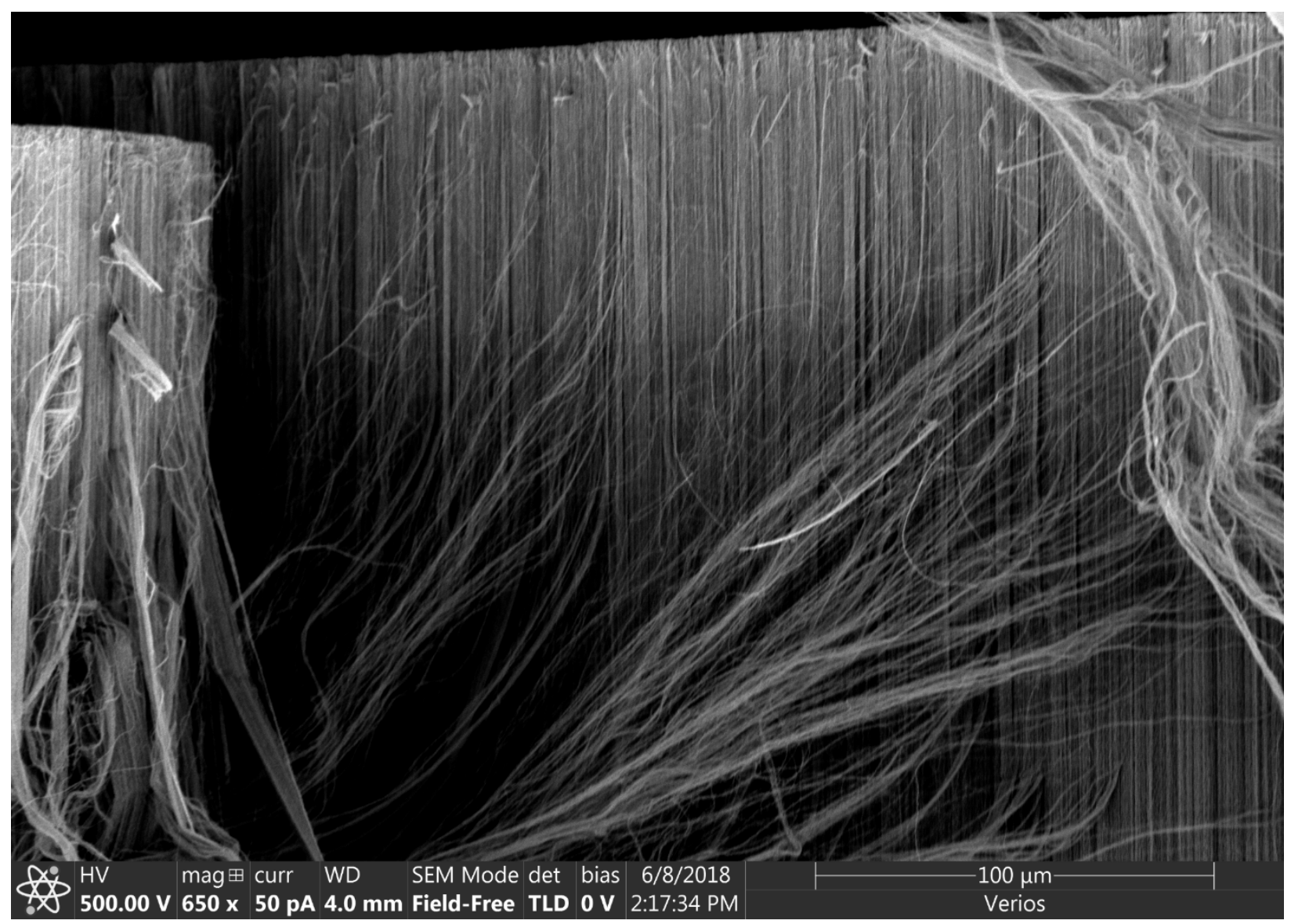

Figure 5 An unsatisfactory image of a MWCNT forest which should have ALD steps.

It appears that forests of a height less than $500 \mu \mathrm{m}$ never cleave cleanly and that taller forests are more likely to cleave cleanly than short ones. However, height is not the only important factor in whether forests cleave well. Of the six MWCNT samples used for the data in this study each one cleaved well, but of another set grown under the same parameters a few weeks later none cleaved cleanly. Figure 5 is an example of this set.

\subsection{Determination of nucleation site density}

To find the nucleation site density for $\mathrm{ALD} \mathrm{Al}{ }_{2} \mathrm{O}_{3}$ on MWCNTs, a $100 \mu \mathrm{m}$ tall MWCNT forest was prepared using the same technique except that a shorter growth time was used and 10 ALD 
cycles and the TMA doses were $2 \mathrm{~s}$ long. Some of the nanotubes were then scraped off the substrate and into isopropyl alcohol which was then sonicated until the suspension appeared homogenous. A lacey carbon TEM grid was then dipped in the suspension and air dried. The nanotubes were imaged with a TEM (FEI Tecnai TF20) in STEM mode. Discrete $\mathrm{Al}_{2} \mathrm{O}_{3}$ nuclei were visible on the MWCNTs. The nucleation site density was found by counting the nuclei and calculating the surface area of the nanotube from the diameter and visible length. At least 100 nanotubes were measured. Figure 6 shows a typical STEM image used for these measurements.

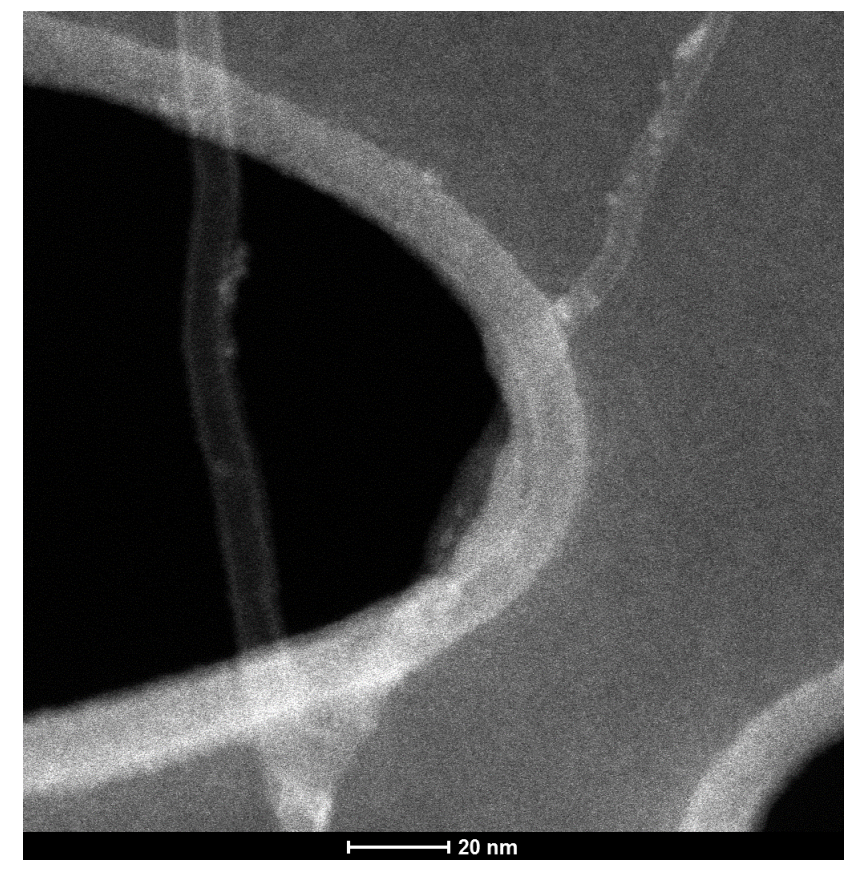

Figure 6 A typical STEM of a MWCNT used for nucleation site density calculations

The ImageJ software ${ }^{58}$ was used to find the ALD nucleation site density from STEM images. The diameter of each clearly visible nanotube portion was measured in three places, and the length was measured to calculate the surface area. The nuclei were counted, and an average value was taken between high and low counts of the nuclei for each nanotube. This was done on over 100 nanotubes 
and the final result is the average. The average nucleation site density was found to be $10^{4} \mu m^{-2}$. It's inverse is the surface area per nucleation site which is about $100 \mathrm{~nm}^{2}$ per site.

\section{MODELLING}

\subsection{Penetration depth model}

We incorporate the conceptual idea of growing nuclei changing the absorption site density into Yanguas-Gil et al.'s model for penetration depth in $\mathrm{ALD}^{31}$. This model provides the needed precursor dose to coat a structure and is based on diffusion of a precursor into a structure with self limiting surface reactions consuming the precursor. It assumes Knudsen diffusion and takes into account the sticking probability in precursor-active site interactions. We modify this model by allowing the adsorption site density to change as the nucleus grows by a simple geometric approach. We model carbon nanotubes after ozone treatment as having some sparsely distributed quantity of active sites, where TMA can adsorb, per unit surface area, $\Gamma_{C N T}$. In the first ALD cycle, a nucleus of $\mathrm{Al}_{2} \mathrm{O}_{3}$ is deposited at each of those sites. We assume that no new active sites appear on the carbon nanotube surface in subsequent cycles. In each subsequent cycle, we model the nucleus as growing as a hemisphere of $\mathrm{Al}_{2} \mathrm{O}_{3}$ with the radius increasing by the growth per cycle (GPC), as illustrated in Figure 7. Each nucleus increases in surface area with each subsequent cycle, and the number of TMA molecules it can absorb in each new cycle is proportional to its surface area.

As the TMA adsorption site density increases with each cycle, the penetration depth of ALD doses decreases dramatically during the first few cycles of the ALD process. We do not account for coalescence of the nuclei in our model. When this occurs, our model no longer applies. 

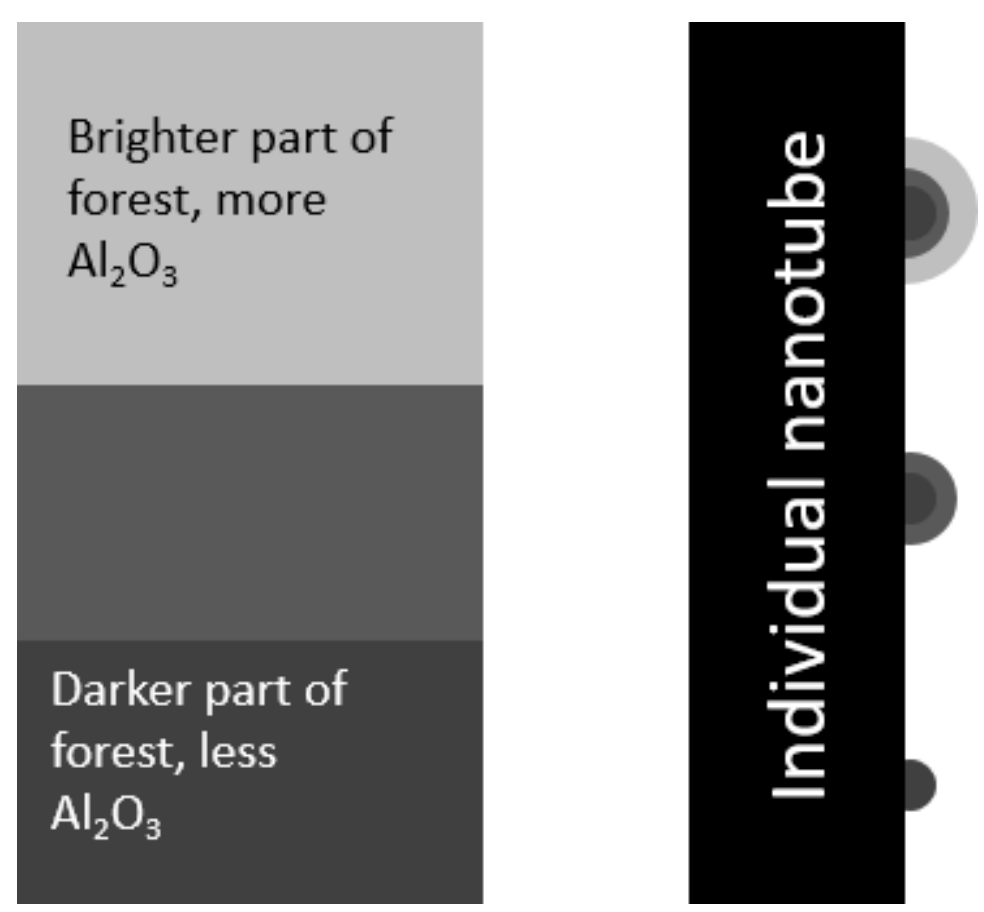

Figure 7 Graphical description of model: Each ALD cycle makes the nuclei grow, causing them to absorb more TMA on subsequent cycles.

Based on these assumptions, we expect the total nucleation site density to be the product of the initial nanotube adsorption site density $\Gamma_{C N T}\left(\frac{\text { sites }}{\mathrm{cm}^{2}}\right)$ and the current number of adsorption sites per nucleus. The number of adsorption sites per nucleus is assumed to be the product of the adsorption sites per unit surface area on a flat hydroxyl terminated $\mathrm{Al}_{2} \mathrm{O}_{3}$ surface $\left(\Gamma_{A l 203}\right)$ and the nucleus surface area:

$$
\Gamma_{\text {total }}=\Gamma_{C N T} \Gamma_{A l 2 O 3} A_{\text {nucleus }}
$$

\section{Equation 3-1}

The nucleus is a hemisphere of radius given by the product of the growth per cycle and the number of elapsed cycles with surface area of : 


$$
A_{\text {nucleus }}=\frac{4 \pi r_{\text {nucleus }}^{2}}{2}=2 \pi\left(\operatorname{GPC}\left(n_{\text {cycle }}-1\right)\right)^{2}
$$

\section{Equation 3-2}

This is a continuum model which does not predict an integer number of atoms will be deposited. It is best applied after enough cycles have elapsed that the decimal (non-integer) part of the number of atoms deposited is small in comparison to the number of atoms deposited. Thus, it is modified to consider a starting size of the nucleus:

$$
A_{\text {nucleus }}=2 \pi\left(G P C\left(n_{\text {cycle }}-n_{i}\right)+r_{i}\right)^{2}=2 \pi G P C^{2}\left(n_{\text {cycle }}-n_{i}+\frac{r_{i}}{G P C}\right)^{2}
$$

\section{Equation 3-3}

where $r_{i}$ is the radius of the nuclei at the starting cycle, $n_{i}$. Each nucleus begins as a single binding site and grows with each cycle, the starting cycle, $\mathrm{n}_{\mathrm{i}}$ is the cycle when the model is applied.

The total adsorption site density or its inverse, the surface area per adsorption site is:

$$
\frac{1}{s_{0}}=\Gamma_{\text {total }}=\Gamma_{C N T} \Gamma_{A l 203} 2 \pi G P C^{2}\left(n_{\text {cycle }}-n_{i}+\frac{r_{i}}{G P C}\right)^{2}
$$

Equation 3-4

\begin{tabular}{|c|l|}
\hline$C$ & $\begin{array}{l}\text { Step coverage of deposited material (ratio of } \\
\text { thickness at bottom to thickness at top) }\end{array}$ \\
\hline$D$ & Knudsen diffusion constant \\
\hline$D$ & Nanotube diameter \\
\hline GPC & Growth Per Cycle \\
\hline$L$ & Penetration distance \\
\hline$M$ & Precursor molecular mass \\
\hline$n_{\mathrm{i}}$ & Number of cycles before model applied \\
\hline$n_{0}$ & $\begin{array}{l}\text { Number density of precursor molecules } \\
\text { injected (per volume) }\end{array}$ \\
\hline
\end{tabular}




\begin{tabular}{|c|c|}
\hline$P$ & Precursor partial pressure \\
\hline $\mathrm{r}_{\mathrm{i}}$ & Radius of nucleus after $n_{i}$ cycles elapsed \\
\hline$S$ & Pore surface area \\
\hline $\bar{s}$ & Pore surface area per unit pore volume \\
\hline$s_{0}$ & Surface area of an adsorption site \\
\hline$T$ & Exposure time \\
\hline$T$ & Temperature \\
\hline$V$ & Pore volume \\
\hline$v_{t h}$ & Thermal velocity \\
\hline$\alpha$ & $\begin{array}{l}\alpha=\frac{1}{4} L^{2} \bar{S} \frac{v_{t h}}{D} \beta_{0} \text { which is the ratio between the } \\
\text { reaction rate and the diffusion rate, defined by } \\
\text { Yanguas-Gil et al. }{ }^{31}\end{array}$ \\
\hline$\beta_{0}$ & $\begin{array}{l}\text { Precursor sticking probability (assuming the } \\
\text { precursor molecule hits an unoccupied site) }\end{array}$ \\
\hline$\Gamma_{A l 2 O 3}$ & $\begin{array}{l}\text { TMA adsorption sites per unit } \mathrm{A} 12 \mathrm{O} 3 \text { surface } \\
\text { area }\end{array}$ \\
\hline$\Gamma_{C N T}$ & $\begin{array}{l}\text { Nucleation sites per unit carbon nanotube } \\
\text { surface area }\end{array}$ \\
\hline$\Gamma_{\text {total }}$ & $\begin{array}{l}\text { TMA adsorption sites per unit nanotube } \\
\text { surface area, counting multiple adsorption } \\
\text { sites on each nucleus }\end{array}$ \\
\hline$\gamma$ & $\begin{array}{l}\gamma=\frac{V n_{0} s_{0}}{S} \text { which is the maximum possible } \\
\text { number of precursor molecules in the } \\
\text { structure divided by the number of adsorption } \\
\text { sites, defined by Yanguas-Gil et al. }{ }^{31}\end{array}$ \\
\hline$\sigma$ & Areal density of carbon nanotubes \\
\hline
\end{tabular}

Table 1 List of variables used

Yanguas-Gil and Elam found a relationship between Knudsen diffusion penetration distance and exposure time, which is applicable to any nanostructured material, as a function of the diffusion constant for a given geometry. ${ }^{31}$

$$
t=\frac{L^{2}}{D} \frac{1}{\gamma}\left(1-\frac{\log (1-c)}{\alpha}\right)
$$

Equation 3-5 
where $\mathrm{t}$ is the dose time, $\mathrm{L}$ is the height of the nanostructure, $\gamma$ and $\alpha$ are dimensionless parameters given in Table 1, and $\mathrm{c}$ is the step coverage (the ratio of the thickness deposited at the top of the structure to the thickness deposited at the depth L). If $\alpha$ is large, that is, if the reaction rate is much larger than the diffusion rate as is typically the case in ALD on a high aspect ratio structure Equation 3-5 can be simplified to:

$$
t=\frac{L^{2}}{D} \frac{1}{\gamma}
$$

\section{Equation 3-6}

Or

$$
L=\sqrt{\gamma D t}
$$

\section{Equation 3-7}

Several values are needed to find $\gamma$ and make use of Equation 3-7. The approximate ratio of the pore surface area to the pore volume is $\bar{s}=\frac{S}{V}=\sigma \pi d$. In calculating $\bar{s}$ it is assumed that the volume of the carbon nanotubes is small in relation to the total volume, as in our forests they occupy less than $1 \%$ of the total volume. Using an ideal gas approximation, we can replace the number density of precursor molecules with $n_{0}=\frac{P}{k_{B} T}$. Upon substituting these values into the dimensionless parameter $\gamma$ in Equation 3-7, we find:

$$
L=\sqrt{\frac{P t s_{0} D}{\pi \sigma d k_{B} T}} .
$$

Equation 3-8 
Using the surface area per adsorption site from Equation 3-4 the penetration depth as a function of cycle number becomes:

$$
L=\sqrt{\frac{P t D}{2 \sigma d k_{B} T \Gamma_{C N T} \Gamma_{A l 203}}} \frac{1}{\pi G P C\left(n_{\text {cycle }}-n_{i}+\frac{r_{i}}{G P C}\right)}
$$

\section{Equation 3-9}

The diffusion coefficient can be found by fitting the experimentally measured penetration depth to Equation 3-9.

\subsection{Step edge profile and sticking coefficient}

Using the step coverage $\mathrm{c}$ as a function of depth (i.e. the shape of the step edge), the Yanguas-Gil model allows us to estimate the sticking coefficient $\beta_{0}$. A simple rearrangement of Equation 3-5 yields:

$$
c=1-e^{\left[\frac{1}{4} \bar{s} v_{t h} \beta_{0}\left(\frac{L^{2}}{D}-\gamma t\right)\right]}
$$

Equation 3-10

$\frac{L^{2}}{D}$ is proportional to the characteristic diffusion time (that is, the time needed for precursor molecules to diffuse a distance $\mathrm{L}$ ); $\gamma t$ is a time modified by a factor determined by the ratio of the number of precursor molecules in the dose to the number of adsorption sites. When time is sufficiently long and $\mathrm{L}$ is short the exponential term will be insignificant, $\mathrm{c}$ will be approximately 1, and the coverage will be uniform to depth L. As $\frac{L^{2}}{D}$ approaches $\gamma t$ the exponential term will become significant and the coverage will drop. When $\frac{L^{2}}{D}$ equals $\gamma t$ the coverage reaches zero. Note that this is the same point where Equation 3-6 is satisfied. How rapidly c drops from 1 to 0 depends 
upon $\bar{s}$, (a geometric factor), the thermal velocity $\mathrm{V}$ th, and the sticking coefficient $\beta_{0}$. As c cannot be less than zero, the coverage should be piecewise defined as:

$$
c=\left\{\begin{aligned}
1-e^{\left[\frac{1}{4} \bar{s} v_{t h} \beta_{0}\left(\frac{L^{2}}{D}-\gamma t\right)\right]}, \frac{L^{2}}{D} \leq \gamma t \\
0, \frac{L^{2}}{D}>\gamma t
\end{aligned}\right.
$$

Equation 3-11

The thermal velocity is given by $v_{t h}=\sqrt{\frac{8 k_{B} T}{\pi m}}$.

\section{RESULTS AND DISCUSSION}

\subsection{Imaging results and analysis}

Two sets of carbon nanotube forest samples were prepared according to the above process. We note that dose times were picked for these samples, based on previous depositions, to study the observed steps. Much shorter doses would have led to insufficient variation in penetration depth to produce multiple steps. Much longer doses would have coated the forest entirely, without producing steps. In the first set, shown in Figure 4, the TMA dose time was fixed at $256 \mathrm{~ms}$ and the number of ALD cycles was 4, 7, and 10. In the second set, shown in Figure 8, the number of cycles was fixed at 10 but the TMA dose times were 64, 128, 256, and $512 \mathrm{~ms} .1 \mathrm{~s}$ water doses 


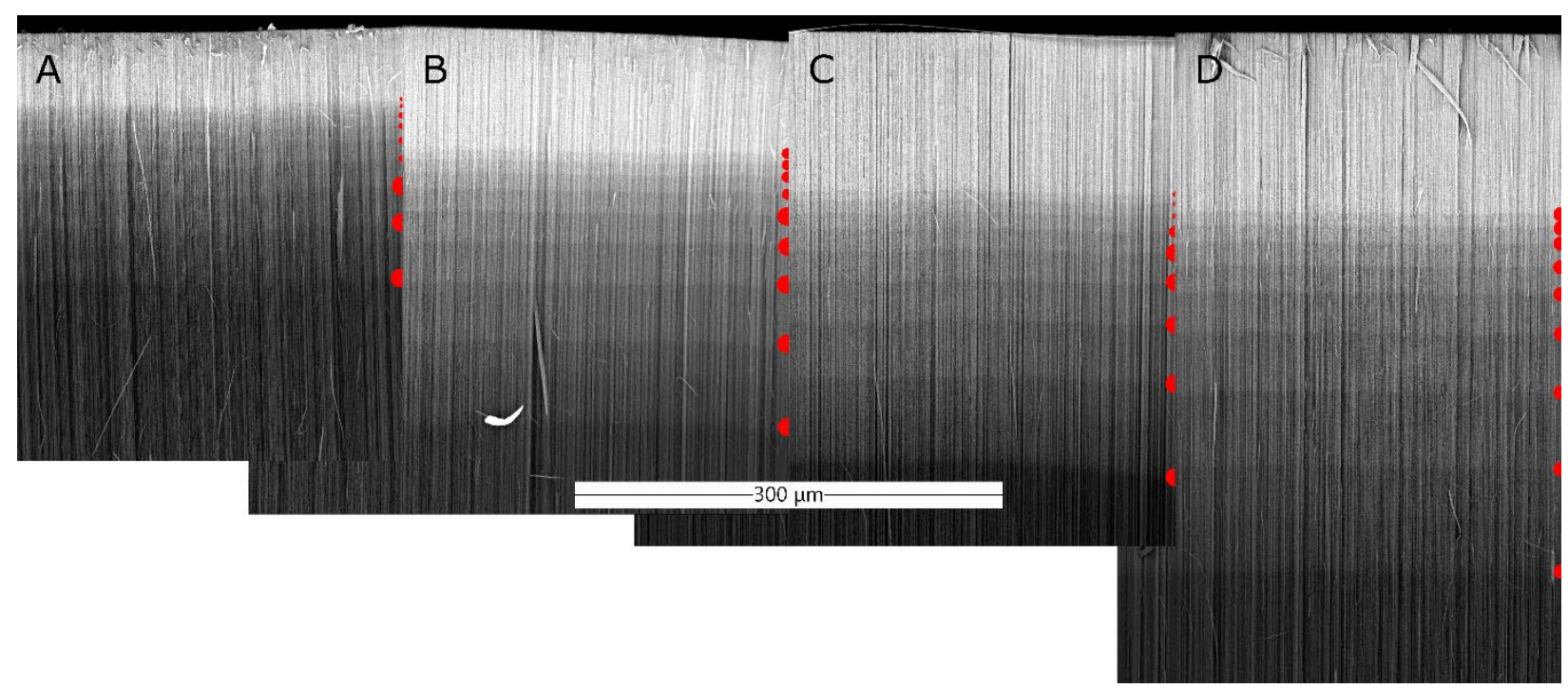

Figure 8 Carbon nanotube forests with 10 ALD cycles and different TMA doses A: 64 ms. B: 128 ms. C:

256 ms. D: 512 ms. Red dots denote edges between steps.

were used on all samples. The longer water dose was selected to ensure complete water exposure. The limiting reactant is TMA. In each SEM image a red dot on the right indicates a step transition. We note that while there was some sample to sample variation, the following features are seen: the number of steps is one less than the number of ALD cycles used in that sample, when increasing the number of ALD cycles, more steps appear at the top of the forest without affecting the ones below, the relative spacing of steps decreases with step number, and increasing the TMA dose time increases the depth and spacing of the step edges. Based on the first two observations, we attribute each step to an ALD cycle with the deepest observed step being attributed to the second cycle and the shallowest to the last cycle. The dose variation observations are shown in Figure 11 where the depth (measured from the forest top) of the step edges have been extracted from Figure 2. 


\subsection{Extraction of diffusion constant}

All terms in Equation 3-9 are known or can be measured. By keeping the sample characteristics and ALD process parameters the same, we can write Equation 3-9 as:

$$
L=\frac{C}{n_{\text {cycle }}-n_{i}+\frac{r_{i}}{G P C}}
$$

Equation 4-1

If the first cycle were the starting point ( $\mathrm{n}_{\mathrm{i}}$ is 1 and $\mathrm{r}_{\mathrm{i}}$ is 0 ) we see the first cycle should penetrate an infinite depth. This is of course non-physical and outside of the model constraints but does indicate that the first cycle penetration should be much larger than subsequent cycles. A first cycle penetration that reached the bottom of the forest would not produce an observable step and result in observed steps being one less than the number of cycles.

The proportionality constant $\mathrm{C}$ includes constants that are fixed in the experimental conditions ( $\mathrm{T}$ $\left(332{ }^{\circ} \mathrm{C}\right), \mathrm{P}(36 \mathrm{~Pa}$, the partial pressure of TMA), and $\mathrm{t}$ (as selected)), a measureable function of the nanotube forest $\left(\sigma\left(120 \mu \mathrm{m}^{-2}\right), \mathrm{d}(11 \mathrm{~nm})\right.$, and $\left.\Gamma_{\mathrm{CNT}}\left(600 \mu \mathrm{m}^{-2}\right)\right)$, or available in the literature or derived from literature values $\left(\mathrm{GPC}(0.8 \mathrm{~nm} /\right.$ cycle $)$ and $\left.\Gamma_{\mathrm{Al} 2 \mathrm{O} 3}\left(3.7 \mathrm{~nm}^{-2}\right)\right)$. The diffusion constant D of gas diffusion in CNT forests is not an experimentally known quantity but can be extracted from a model fit to the step edge depths. Theoretical work by Szmyt et al. ${ }^{53}$ predicts a diffusion constant of $5 \frac{\mathrm{cm}^{2}}{\mathrm{~s}}$.

The constant $\mathrm{C}$ was measured by fitting to the step depth data from SEM images. To fit Equation 4-1 to the data, ni was set to 3 and the first two cycles were not used in the fit. The arbitrary choice of the number of cycles not used in the fit was intended to produce a good fit. The parameter $\frac{r_{i}}{G P C}$ was then determined to be 4.3 by fitting. Examples of this fit are shown in figure $3 \mathrm{~B}$ and figure 
3C. The model is not fit to data below the third cycle. However, the interpolation of the model below the third cycle predicts a much greater penetration than observed. This is due to the model allowing fractional atomic coverage, smaller resulting surface area, and corresponding greater penetration than discrete atomic deposition would allow. We recognize that the choice of fitting from cycle 3 and above is somewhat arbitrary.

Once the proportionality constant is obtained from the experimental data the diffusion constant can be calculated.

$$
D=\frac{2 \pi^{2} C^{2} G P C^{2} \sigma d k_{B} T \Gamma_{C N T} \Gamma_{A l 2 O 3}}{P t}
$$

\section{Equation 4-2}

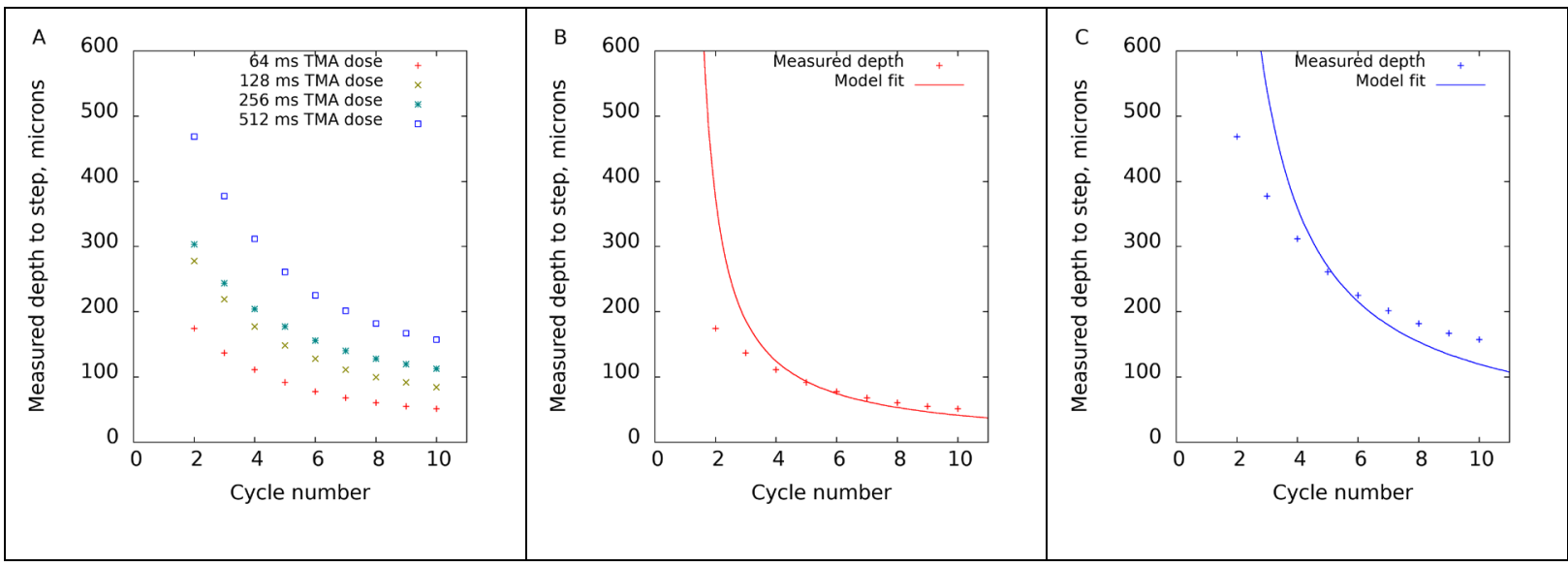

Figure 9 A: Cycle penetration depths from four MWCNT forests, each with 10 ALD cycles with 64, 128,

256, and 512 ms TMA doses. B: Data from the 64ms dose sample, along with the model fit. C: Data from the $512 \mathrm{~ms}$ dose sample, along with the model fit.

The average diffusion constant (from the four time varied samples) was $0.3 \frac{\mathrm{cm}^{2}}{\mathrm{~s}} \pm 75 \%$. The uncertainty is propagated from error in measurements of parameters, and is heavily increased by 
the uncertainty in the measurements of the areal CNT density and CNT diameter in MWCNT forests.

There are simplifications made in our model. We do not consider the variation in areal carbon nanotube density ${ }^{59}$ or average nanotube diameter between the top and bottom of a forest, or any variation in other parameters which might depend on the depth in the forest. We assume no desorption or surface diffusion of TMA and that new nucleation sites do not appear after the first cycle.

\subsection{Sticking coefficient calculation}

The sticking coefficient $\beta_{0}$, a number between 0 and 1 , is the probability that a precursor molecule will attach to the surface when it impinges on it. Equation 3-11 predicts a relation between step coverage as a function of position (shape of the step edge) and the sticking coefficient $\beta_{0} . \beta_{0}$ affects the abruptness of the intensity steps. A line profile extracted from a SEM image is used as a relative measurement of the surface coverage as a function of penetration depth.

To determine the sticking coefficient $\beta_{0}$, a modification of Equation 3-11 is used:

$$
\text { Intensity }=\left\{\begin{array}{r}
a-b e^{\left[\frac{1}{4} \bar{s} v_{t h} \beta_{0}\left(\frac{L^{2}}{D}-\gamma t\right)\right]}, \frac{L^{2}}{D} \leq \gamma t \\
a-b, \frac{L^{2}}{D}>\gamma t
\end{array}\right.
$$

Equation 4-3

where $\mathrm{a}$ is the intensity in the high intensity region before the intensity drop and $\mathrm{b}$ is the difference between a and the intensity after the intensity drop. Note that $\beta_{0}$ affects how steep the intensity drop is, as shown in Figure 10. 


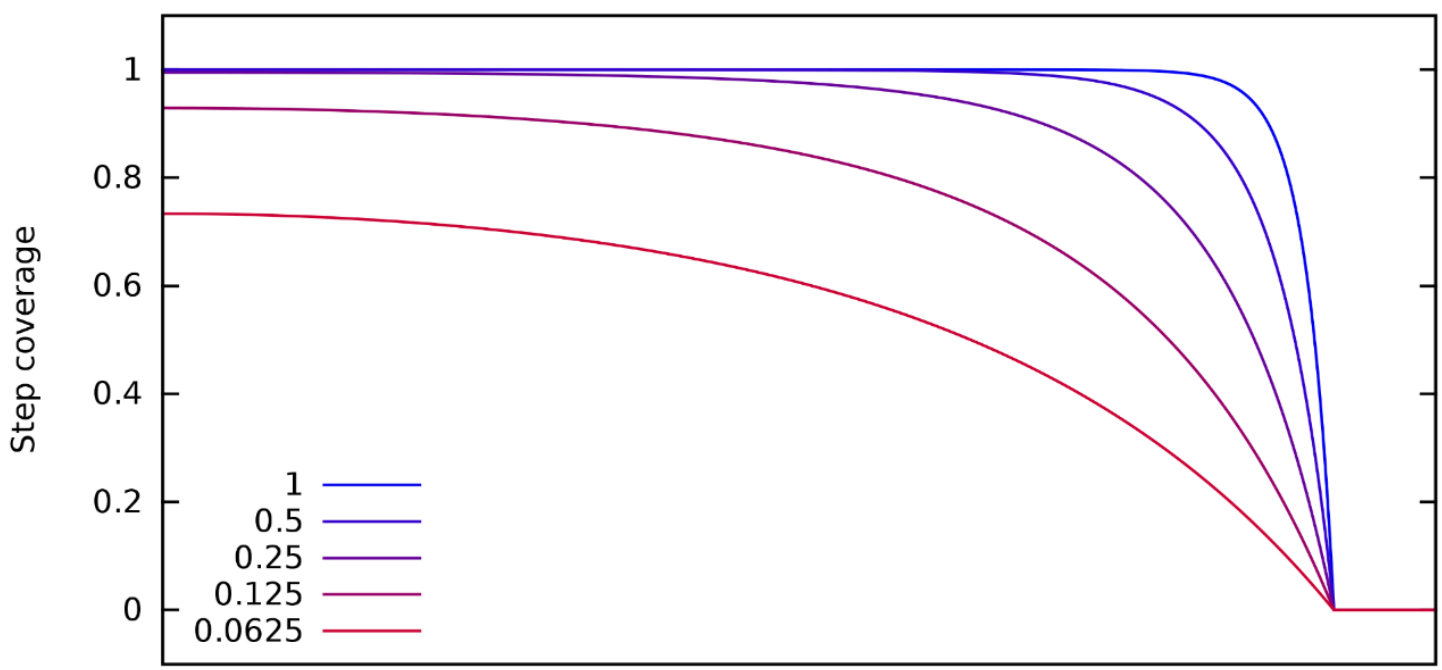

Depth in structure

Figure 10 Effect of sticking coefficient on step coverage profile. Parameters chosen for demonstration.

The sticking coefficient was measured from a 1500 pixel wide line profile which was manually aligned to the steps using the Gwyddion software. ${ }^{60}$ The line profile used to find the reported values is shown in Figure 11. In the line profile, steps corresponding to the steps are visible. The line profile was manually split into segments corresponding to each dose consisting of the intensity drop from a single cycle and the adjacent flat regions.

For each of those segments, Equation 4-3 was fit by varying $\gamma$ and $\beta_{0}$ by the nonlinear least squares method. The maximum and minimum intensity variables $\mathrm{a}$ and $\mathrm{b}$ were found by averaging the intensity values in the appropriate region.. 


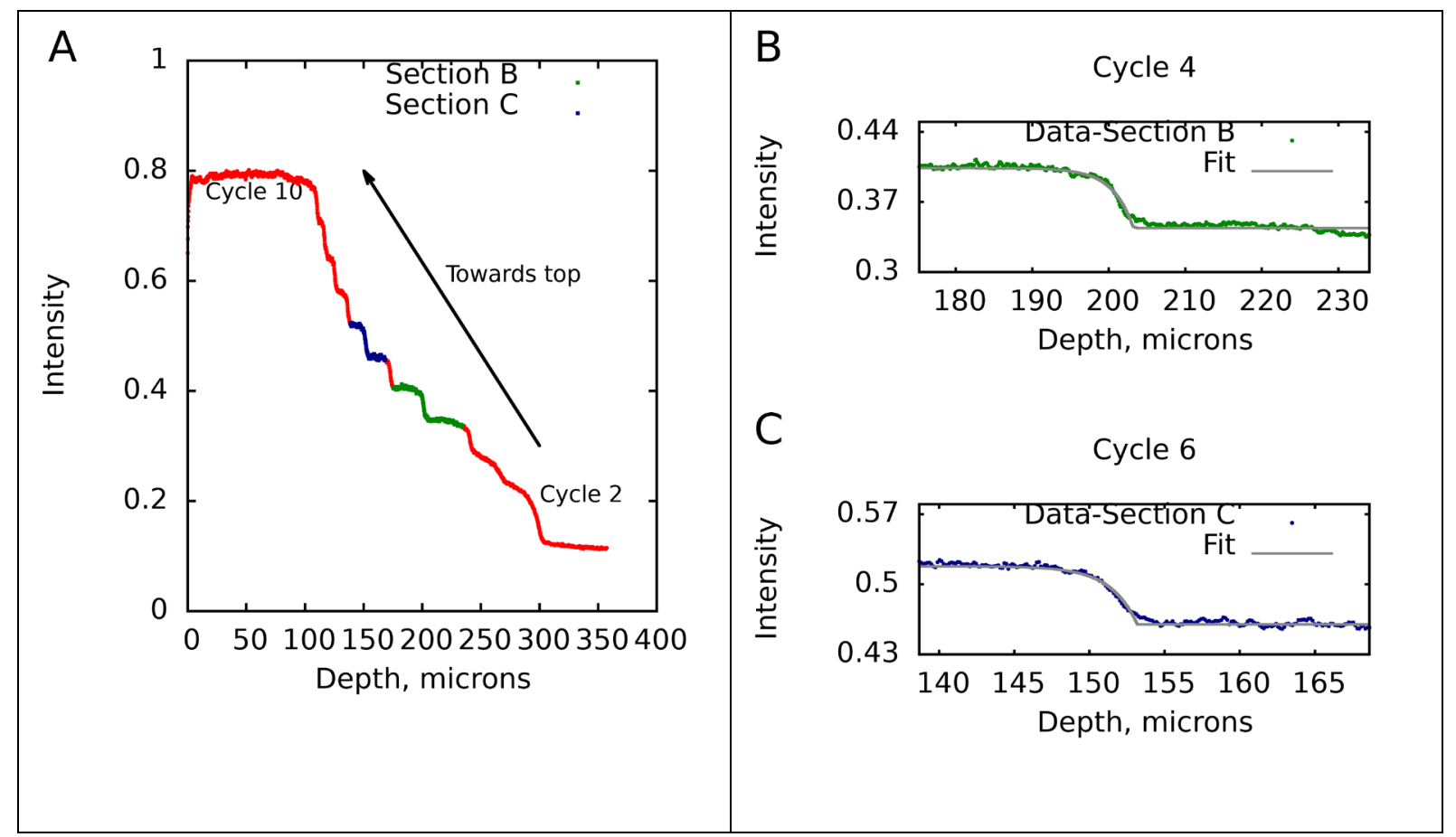

Figure 11 A: SEM intensity profile from MWNCT forest with 10 aluminum oxide ALD cycles and $256 \mathrm{~ms}$

TMA doses. $B$ and $C$ are segments of the intensity profile in $A$ with the intensity fit used to find $\beta_{0 .}$.

Fitting Equation 3-11 to a segment of the intensity profile by varying $\beta$ gives the probability that a TMA molecule will stick to the decorated carbon nanotube surface. This quantity is not $\beta_{0}$ because only a small fraction of the carbon nanotube surface is covered with reactive, hydroxyl terminated $\mathrm{Al}_{2} \mathrm{O}_{3}$. The most likely result of a collision with this CNT surface is that the TMA molecule will simply bounce off without impinging on a reactive site. $\beta_{0}$ is the probability that the TMA molecule will stick if it hits a hydroxylated alumina surface. To obtain $\beta_{0}$, a correction for the fraction of surface area covered with $\mathrm{Al}_{2} \mathrm{O}_{3}$ must be applied. The surface area correction is calculated from the radius of the nuclei, GPC $\left(n_{c y c l e}-n_{i}+\frac{r_{i}}{G P C}\right)$, the cycle number at that step, and the density of active sites (which is also the density of nuclei) on the carbon nanotubes $\Gamma_{\mathrm{CNT}}$. The same offset values $n_{i}=3$ and $\frac{r_{i}}{G P C}=4.3$ used above are used to calculate the radius. The corrected value of $\beta_{0}$ is given by: 


$$
\begin{gathered}
\beta_{0}=\frac{\beta_{\text {measured }}}{\pi(G P C)^{2}(n+1.3)^{2} \Gamma_{C N T}} \\
\text { Equation 4-4 }
\end{gathered}
$$

The calculated values of $\beta_{0}$ can be seen in Figure 12 .

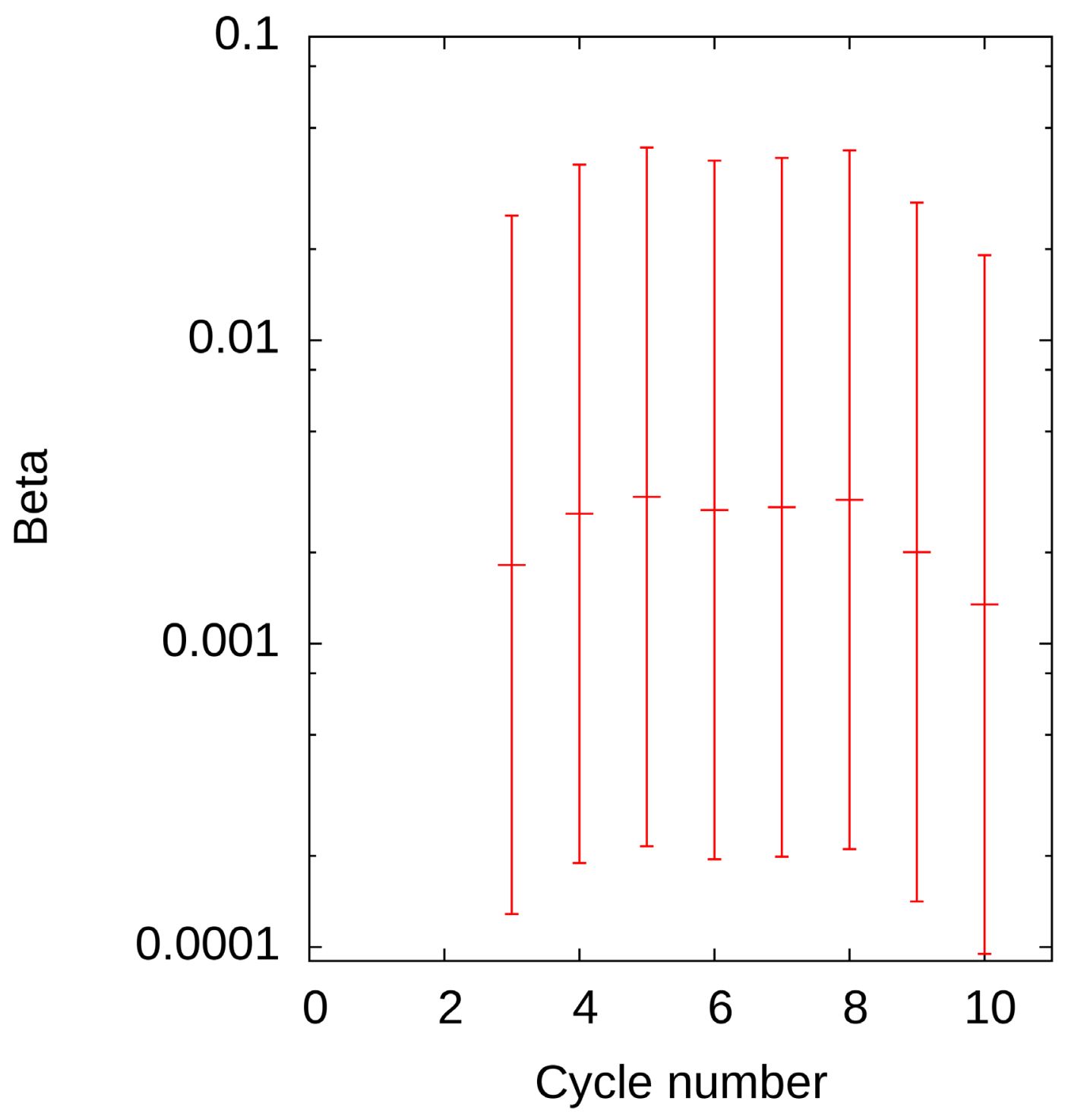

Figure 12 Sticking coefficient values for different ALD cycles. Note that systematic error is much greater than statistical fluctuation. 
Some of the intensity steps were not used due to the effects of image defects, as visible in Figure 11. Cycles 9 and 10 have very short available profiles. Because of defects in the MWCNT forest, the intensity steps are not completely parallel, possibly distorting the shape of these narrow intensity steps and adversely affecting the fit for $\beta_{0}$. Cycle 3 does not have a flat region on the low intensity side of the decrease in intensity. This is needed to accurately determine $\gamma$. Without a reliable estimate for $\gamma$, the estimate of $\beta_{0}$ is unreliable.

Based on an average of the $\beta_{0}$ values with the propagated experimental error, we expect $\beta_{0}$ to lie between $2 \times 10^{-4}$ and $5 \times 10^{-2}$ with the most likely value being $3 \times 10^{-3}$. Values reported in the literature are somewhat higher, 0.02 from $200^{\circ} \mathrm{C}$ to $300^{\circ} \mathrm{C}^{32}$ and $5.7 \times 10^{-3}$ at $300^{\circ} \mathrm{C}^{61}$.

\section{SUMMARY AND CONCLUSIONS}

We have observed concentration steps in ALD on MWCNT forests where each subsequent cycle penetrated less distance into the forest. We explain this behavior by Knudsen diffusion combined with increased consumption of precursor due to the increasing surface area of each deposited nucleus. Based on cycle number experiments on multiple samples, we claim that each step was formed by a single ALD cycle. Existing models allow us to determine the diffusion constant in the MWCNT forest from our penetration depth data and the sticking coefficient from the shape of the steps. The diffusion coefficient for TMA in MWCNT forests was $0.3 \mathrm{~cm}^{2} / \mathrm{s}$ and the sticking probability for TMA in the TMA/water ALD process was 0.003 . This sticking coefficient value is slightly lower than those available in the literature. 


\section{References}

${ }^{1}$ G. Fiorentino, S. Vollebregt, F.D. Tichelaar, R. Ishihara, and P.M. Sarro, Nanotechnology 26, $064002(2015)$

${ }^{2}$ C.L. Pint, N.W. Nicholas, S. Xu, Z. Sun, J.M. Tour, H.K. Schmidt, R.G. Gordon, and R.H. Hauge, Carbon 49, 4890 (2011).

3 A.M. Saleem, R. Andersson, V. Desmaris, and P. Enoksson, Solid-State Electronics 139, 75 (2018).

${ }^{4}$ Y. Li, J. Jiang, C. Zhu, L. Li, Q. Li, Y. Ding, and W. Yang, Materials 11, 172 (2018).

${ }^{5}$ Y. Wang, S.L. Marquard, D. Wang, C. Dares, and T.J. Meyer, ACS Energy Lett. 2, 1395 (2017).

${ }^{6}$ Weber Matthieu, Collot Philippe, El Gaddari Hoda, Tingry Sophie, Bechelany Mikhael, and Holade Yaovi, ChemElectroChem 5, 743 (2018).

${ }^{7}$ J. Liu, P. Zhou, T. Han, J. Huang, J. Liu, J. Li, and P.V. Braun, Materials Letters 219, 12 (2018).

${ }^{8}$ J.-W. Jung, D.-W. Choi, C.K. Lee, K.R. Yoon, S. Yu, J.Y. Cheong, C. Kim, S.-H. Cho, J.-S. Park, Y.J. Park, and I.-D. Kim, Nano Energy 46, 193 (2018).

9 Wen Liaoyong, Zhou Min, Wang Chengliang, Mi Yan, and Lei Yong, Advanced Energy Materials 6, 1600468 (2016).

${ }^{10}$ S.M. George, Chem. Rev. 110, 111 (2010).

${ }^{11}$ R.W. Johnson, A. Hultqvist, and S.F. Bent, Materials Today 17, 236 (2014).

12 A. Yanguas-Gil, Growth and Transport in Nanostructured Materials: Reactive Transport in PVD, CVD, and ALD (Springer International Publishing, 2017).

${ }^{13}$ H. Seidl, M. Gutsche, U. Schroeder, A. Birner, T. Hecht, S. Jakschik, J. Luetzen, M. Kerber, S. Kudelka, T. Popp, A. Orth, H. Reisinger, A. Saenger, K. Schupke, and B. Sell, in Digest. International Electron Devices Meeting, (2002), pp. 839-842. 
${ }^{14}$ H. Sakurai and H. Tomita, US7096548 (29 August 2006).

${ }^{15}$ R. Katsumata and H. Aochi, US7019349 (28 March 2006).

${ }^{16}$ H. Chen, E. Haywood, S. Malhotra, and H. Ode, US8829647B2 (9 September 2014).

${ }^{17}$ J.W. Elam, D. Routkevitch, P.P. Mardilovich, and S.M. George, Chem. Mater. 15, 3507 (2003).

${ }^{18}$ M. Ohring, Materials Science of Thin Films (Elsevier Science \& Technology, Burlington, UNITED STATES, 2001).

${ }^{19}$ S. Ganguli, S.P. Costello, and W.N. Gill, Ind. Eng. Chem. Res. 34, 3380 (1995).

${ }^{20}$ A. Yanguas-Gil, Y. Yang, N. Kumar, and J.R. Abelson, Journal of Vacuum Science \& Technology A 27, 1235 (2009).

${ }^{21}$ R.L. Puurunen, Chemical Vapor Deposition 20, 332 (n.d.).

22 J. Vila-Comamala, L. Romano, V. Guzenko, M. Kagias, M. Stampanoni, and K. Jefimovs, Microelectronic Engineering 192, 19 (2018).

${ }^{23}$ J. S. Daubert, R. Wang, J. S. Ovental, H. F. Barton, R. Rajagopalan, V. Augustyn, and G. N. Parsons, Journal of Materials Chemistry A 5, 13086 (2017).

${ }^{24}$ P. Poodt, A. Mameli, J. Schulpen, W.M.M. (Erwin) Kessels, and F. Roozeboom, Journal of Vacuum Science \& Technology A: Vacuum, Surfaces, and Films 35, 021502 (2016).

${ }^{25}$ F. Grillo, M.T. Kreutzer, and J.R. van Ommen, Chemical Engineering Journal 268, 384 (2015).

${ }^{26}$ T. Keuter, N.H. Menzler, G. Mauer, F. Vondahlen, R. Vaßen, and H.P. Buchkremer, Journal of Vacuum Science \& Technology A: Vacuum, Surfaces, and Films 33, 01 A104 (2014).

${ }^{27}$ S.O. Kucheyev, J. Biener, T.F. Baumann, Y.M. Wang, A.V. Hamza, Z. Li, D.K. Lee, and R.G. Gordon, Langmuir 24, 943 (2008).

${ }^{28}$ J.-Y. Kim, J.-H. Ahn, S.-W. Kang, and J.-H. Kim, Journal of Applied Physics 101, 073502 (2007). 
${ }^{29}$ A.V. Fadeev, A.V. Myakon'kikh, and K.V. Rudenko, Tech. Phys. 63, 235 (2018).

${ }^{30}$ R.G. Gordon, D. Hausmann, E. Kim, and J. Shepard, Chem. Vap. Deposition 9, 73 (2003).

${ }^{31}$ A. Yanguas-Gil and J.W. Elam, Chem. Vap. Deposition 18, 46 (2012).

${ }^{32}$ M.C. Schwille, T. Schössler, F. Schön, M. Oettel, and J.W. Bartha, Journal of Vacuum Science \& Technology A: Vacuum, Surfaces, and Films 35, $01 B 119$ (2016).

${ }^{33}$ M. Rose and J.W. Bartha, Applied Surface Science 255, 6620 (2009).

${ }^{34}$ M. Rose, J.W. Bartha, and I. Endler, Applied Surface Science 256, 3778 (2010).

${ }^{35}$ Y. Saiki, Y. Fan, and Y. Suzuki, Combustion and Flame 162, 4036 (2015).

${ }^{36}$ J.W. Elam, C.E. Nelson, R.K. Grubbs, and S.M. George, Surface Science 479, 121 (2001).

37 Y. Hayamizu, T. Yamada, K. Mizuno, R.C. Davis, D.N. Futaba, M. Yumura, and K. Hata, Nature Nanotechnology 3, 289 (2008).

${ }^{38}$ G. Chen, B. Dodson, D.M. Hedges, S.C. Steffensen, J.N. Harb, C. Puieo, C. Galligan, J. Ashe, R.R. Vanfleet, and R.C. Davis, ACS Biomater. Sci. Eng. 4, 1900 (2018).

${ }^{39}$ C. Silvestri, M. Riccio, R.H. Poelma, A. Jovic, B. Morana, S. Vollebregt, A. Irace, G.Q. Zhang, and P.M. Sarro, Small 14, 1800614 (n.d.).

${ }^{40}$ C. Marichy and N. Pinna, Coordination Chemistry Reviews 257, 3232 (2013).

${ }^{41}$ E. Kao, C. Yang, R. Warren, A. Kozinda, and L. Lin, Sensors and Actuators A: Physical 240, 160 (2016).

${ }^{42}$ A.A. Dameron, S. Pylypenko, J.B. Bult, K.C. Neyerlin, C. Engtrakul, C. Bochert, G.J. Leong, S.L. Frisco, L. Simpson, H.N. Dinh, and B. Pivovar, Applied Surface Science 258, 5212 (2012).

${ }^{43}$ R. Warren, F. Sammoura, F. Tounsi, M. Sanghadasa, and L. Lin, J. Mater. Chem. A 3, 15568 (2015).

${ }^{44}$ J. Zhang, C. Chen, S. Chen, Q. Hu, Z. Gao, Y. Li, and Y. Qin, Catal. Sci. Technol. 7, 322 (2017). 
${ }^{45}$ S.M. George, A.S. Cavanagh, C.A. Wilson, and A.W. Weimer, Nanotechnology 20, 255602 (2009).

${ }^{46}$ Journal of Vacuum Science \& Technology A: Vacuum, Surfaces, and Films 35, $01 B 113$ (2016).

${ }^{47}$ R.M. Silva, M.C. Ferro, J.R. Araujo, C.A. Achete, G. Clavel, R.F. Silva, and N. Pinna, Langmuir 32, 7038 (2016).

${ }^{48}$ Guo-Dong Zhan, Xiaohua Du, D.M. King, L.F. Hakim, X. Liang, J.A. McCormick, and A.W. Weimer, Journal of the American Ceramic Society 91, 831 (2008).

${ }^{49}$ D. Dominguez, H.A. Borbón-Nuñez, J.M. Romo-Herrera, F. Muñoz-Muñoz, E.A. ReynosoSoto, H. Tiznado, and G. Soto, J Mater Sci 53, 2005 (2018).

${ }^{50}$ D.S. Jensen, S.S. Kanyal, N. Madaan, A.J. Miles, R.C. Davis, R. Vanfleet, M.A. Vail, A.E. Dadson, and M.R. Linford, Journal of Vacuum Science \& Technology B, Nanotechnology and Microelectronics: Materials, Processing, Measurement, and Phenomena 31, 031803 (2013).

${ }^{51}$ B. Lee, S.-Y. Park, H.-C. Kim, K. Cho, E.M. Vogel, M.J. Kim, R.M. Wallace, and J. Kim, Appl. Phys. Lett. 92, 203102 (2008).

${ }^{52}$ A. Lushington, J. Liu, Y. Tang, R. Li, and X. Sun, Journal of Vacuum Science \& Technology A 32, $01 \mathrm{~A} 124$ (2013).

${ }^{53}$ W. Szmyt, C. Guerra, and Utke, Ivo, Beilstein J. Nanotechnol. 8, 64 (2017).

${ }^{54}$ J. Song, D.S. Jensen, D.N. Hutchison, B. Turner, T. Wood, A. Dadson, M.A. Vail, M.R. Linford, R.R. Vanfleet, and R.C. Davis, Advanced Functional Materials 21, 1132 (2011).

${ }^{55}$ D.N. Hutchison, N.B. Morrill, Q. Aten, B.W. Turner, B.D. Jensen, L.L. Howell, R.R. Vanfleet, and R.C. Davis, Journal of Microelectromechanical Systems 19, 75 (2010).

${ }^{56}$ P.B. Amama, C.L. Pint, S.M. Kim, L. McJilton, K.G. Eyink, E.A. Stach, R.H. Hauge, and B. Maruyama, ACS Nano 4, 895 (2010). 
57 J. Yang, S. Esconjauregui, R. Xie, H. Sugime, T. Makaryan, L. D’Arsié, D.L. Gonzalez Arellano, S. Bhardwaj, C. Cepek, and J. Robertson, J. Phys. Chem. C 118, 18683 (2014).

${ }^{58}$ C.A. Schneider, W.S. Rasband, and K.W. Eliceiri, Nature Methods (2012).

${ }^{59}$ M. Bedewy, E.R. Meshot, M.J. Reinker, and A.J. Hart, ACS Nano 5, 8974 (2011).

${ }^{60}$ P. Klapetek, D. Nečas, A. Campbellová, A. Yacoot, and L. Koenders, Meas. Sci. Technol. 22, $025501(2011)$.

${ }^{61}$ M. Ylilammi, O.M.E. Ylivaara, and R.L. Puurunen, Journal of Applied Physics 123, 205301 (2018). 